\title{
A VISÃO DE PROFESSORES DE LÍNGUA INGLESA NO ENSINO FUNDAMENTAL I SOBRE SUA FORMAÇÃO INICIAL
}

\author{
Elementary school English teachers' views about their education
}

\author{
Bianca Danielle Sawada VILKEVICIUS \\ Universidade Tecnológica Federal do Paraná \\ biancavilk@gmail.com \\ https://orcid.org/0000-0003-2350-5338 \\ Andressa BRAWERMAN-ALBINI \\ Universidade Tecnológica Federal do Paraná \\ andbraw@utfpr.edu.br \\ https://orcid.org/0000-0003-1402-4145
}

\begin{abstract}
RESUMO: No cenário global atual, há uma grande expansão de escolas bilíngues e escolas regulares que assumem o inglês como disciplina nos primeiros anos, mas muitos de seus professores não tiveram o preparo para lidar com crianças na sua formação. Vários autores mencionam as especificidades desse público, tais como Brown (2001), que ressalta a diferença de atenção entre o aluno criança e o adulto, e Ur (2012), que enfatiza o aprendizado implícito do público infantil. A partir disso, este artigo tem como objetivo investigar a visão dos professores de inglês do Ensino Fundamental I sobre sua formação inicial e se, de acordo com eles, a sua graduação os preparou profissionalmente para o momento da prática. Os dados de análise desta pesquisa foram coletados por meio de um questionário respondido por 14 professores que possuem pelo menos um curso de graduação, seja em Letras ou Pedagogia. Os resultados sugerem que os cursos aceitos como formação de professores de inglês para crianças não preparam totalmente para a prática e necessitam de uma reformulação. PALAVRAS-CHAVE: Criança; Formação; Inglês; Professor.
\end{abstract}

\begin{abstract}
Throughout the world today, there is a large growth of bilingual and monolingual schools that have English as a subject in the first years, but many of their teachers are not prepared to deal with young children. Many authors refer to the different abilities required to work with this public, such as Brown (2001), who mentions the difference in attention between the child and the adult student, and Ur (2012), who emphasizes the implicit learning which happens with children. This paper aims to investigate Elementary school English teachers' view about their initial education and if, according to them,
\end{abstract}


their undergraduate course prepared them professionally for the real-world needs of teachers. The analysis data of this research were collected through a questionnaire answered by 14 teachers who have at least an undergraduate degree, either in English or education. Results suggest that the educational requirements for elementary school English teachers are not fully sufficient and therefore require reformulation. KEYWORDS: Child; Education; English; Teacher.

\section{INTRODUÇÃO}

A língua inglesa (LI) é atualmente considerada uma língua global. Consequentemente, o interesse por ela vem crescendo e, nesse cenário, estamos passando por uma grande expansão de escolas bilíngues e escolas regulares que assumem o inglês como disciplina nos primeiros anos. O professor que se propõe à função de ensinar inglês como língua estrangeira para crianças (ILEC) necessita ter um arsenal de conhecimentos específicos com o objetivo de desenvolver seu trabalho de modo a atender adequadamente as características do contexto em que irá atuar. Para tal, é essencial que esse profissional esteja inserido em um processo de formação inicial que lhe possibilite (re)pensar as questões referentes ao ensino de ILEC. No entanto, o que se observa é que não há uma formação específica para esse profissional dentro da maioria dos cursos de graduação em Letras. Diante desse quadro, surgiu a temática deste artigo: a formação do professor de inglês para crianças. Assim sendo, a pesquisa será realizada com professores de inglês em atuação no Ensino Fundamental I com o intuito de identificar o perfil desses docentes e investigar sua formação inicial.

Este artigo tem como objetivos averiguar se a formação determinada por lei está sendo exigida no momento da seleção dos profissionais e verificar se a formação inicial dos professores de inglês do Ensino Fundamental I lhes dá suporte para o momento da prática ao adentrar o mercado de trabalho de acordo com a visão dos professores entrevistados. Para tanto, a próxima seção explora o ensino de ILEC e aborda a problemática da formação inicial do professor. Ela é seguida pela metodologia adotada nesta pesquisa, pelos resultados obtidos a partir do questionário aplicado e pelas considerações finais.

\section{ENSINO DE INGLÊS COMO LÍNGUA ESTRANGEIRA PARA CRIANÇA E A FORMAÇÃO INICIAL DO PROFESSOR}

Existe uma ampla discussão sobre a relevância do ensino-aprendizagem de ILEC no Brasil. A esse respeito vale citar a entrevista de Rajagopalan concedida a Santos, 
Silva e Justina (2011). Ao ser questionado sobre seu posicionamento acerca do ensino e aprendizagem de línguas estrangeiras para crianças, o pesquisador defende que não é simplesmente fácil estipular uma idade mínima e/ou ideal para iniciar o aprendizado de uma língua estrangeira (LE). Ele explica que se deve pensar na relevância daquele conhecimento para a vida da criança.

No Brasil, ILEC é uma prática bastante comum nas redes privadas atualmente, porém o crescimento do ensino de inglês para crianças já atinge escolas públicas. Um estudo feito por Mello (2013), por exemplo, relata que em Rolândia, um município localizado no interior do Norte do Paraná, foi instituído o ensino da língua inglesa nas escolas pertencentes à rede municipal. Um outro exemplo é Vicentim (2013), que mostra as políticas linguísticas de ensino de língua inglesa para os anos iniciais do Ensino Fundamental I público em Campinas, São Paulo. Esses e outros exemplos revelam o crescimento do ILEC também na rede pública de ensino.

Muitos garantem que quanto mais cedo a exposição a uma LE, mais bem-sucedida será a aprendizagem. Entretanto, Lightbown e Spada (2011) discorrem sobre os casos em que a criança tem contato com uma LE em contexto educacional e, quando fora da escola, continua usando a sua primeira língua:

Quando o objetivo do programa educacional é uma habilidade comunicacional básica para todos os alunos e há um forte comprometimento em manter e desenvolver a primeira língua da criança, pode ser mais eficiente começar o ensino da segunda língua mais $\operatorname{tarde}^{1}$ (LIGHTBOWN; SPADA, 2011, p. 186) ${ }^{2}$.

As autoras ainda se referem aos casos chamados "drip-feed approach", abordagem de ensino por "gotejamento", ou seja, quando os alunos têm uma ou duas horas de aulas de LE por semana, como comumente ocorre nos currículos de escolas regulares. De acordo com as pesquisadoras, essa abordagem pode acontecer por anos seguidos e irá resultar em mais frustrações do que progresso.

Ur (2012) complementa: "Então a resposta para a pergunta 'os alunos mais

\footnotetext{
${ }^{1}$ As citações em inglês neste artigo foram traduzidas pelas autoras e as originais se encontram em notas de rodapé.

${ }^{2}$ When the goal of the educational programme is basic communicative skill for all students, and where there is a strong commitment to maintaining and developing the child's first language, it can be more efficient to begin second language teaching later.
} 
novos aprendem uma língua melhor?' é não, eles não aprendem"3 (p. 257). Ur concorda que alunos adolescentes aprendem de forma diferente dos alunos crianças. Em razão disso, a forma como a LE é ensinada é o fator determinante da qualidade e efetividade da aprendizagem. A autora explica que quanto mais velho o aluno, mais explícito é o processo de aprendizado. Portanto, ele se utiliza de mais estratégias que o aluno criança, como acessar explicações, aprender listas de vocabulário, testar hipótese, entre outras, tendo como resultado uma aprendizagem eficientemente rápida. Já o aluno criança, por ter aprendizado implícito, por memorização, imitação, repetição e brincadeiras, caracterizase por uma aprendizagem que ocorre a longo prazo. Segundo a autora, "quanto mais velhos forem, mais se beneficiarão da instrução. Por isso, é provavelmente insensato insistir que as crianças iniciem o ensino de inglês nos estágios iniciais da escola primária. É preferível investir as horas em um estágio posterior, quando elas podem fazer melhor uso delas" (UR, 2012, p. 257)4.

Percebe-se, assim, que o processo de aprendizagem de uma LE não ocorre de maneira igual entre o público infantil e alunos de outras faixas etárias. Como apresentado por Brewster, Ellis e Girard (2002), o estilo de aprendizagem das crianças tende a ser mais lento do que o dos adultos, principalmente quando se trata de elementos ensinados de forma explícita. Além disso, o público infantil tem menor retenção em comparação com os adultos, o que torna fundamental a revisão de conteúdos durante o processo de ensinoaprendizagem. Sendo assim, o aprendizado infantil é caracterizado por idas e vindas constantes, que tornam a revisão de conteúdos fundamental durante o processo, além de ser importante, como ressaltam Colombo e Consolo (2016), a "exposição frequente do aluno ao insumo" (p. 48).

Ainda, de acordo com Moon (2005), a principal diferença de se ensinar LE para criança é que o profissional necessita ter uma grande capacidade de motivar o aprendiz "despropositado". Crianças não têm capacidade de entender o que é aprender uma LE e, tampouco, perceber a relevância de tal ensinamento (NIKOLOV, 1999).

A criança tem ainda outra grande diferença quando comparada com aprendizes mais velhos: o foco de atenção. Segundo Brown (2001), na criança o foco de atenção é periférico e espontâneo e o interesse é imediato, enquanto o adulto consegue,

\footnotetext{
${ }^{3}$ So the answer to the question 'Do younger learn language better?' Is no, they don't.

${ }^{4}$ the older they are, the more they will benefit from instruction. So it is probably unwise to insist on children starting English in the early stages of primary school, and preferable to invest the hours at later stage, when they can make better use of them (UR, 2012, p. 257).
} 
conscientemente, focar nas formas da língua.

No entanto, o ensino de LE para crianças (LEC) também possui vantagens. Segundo Brown (2001), a criança é mais espontânea, curiosa e natural, ao ser menos temerosa ao erro, ao passo que o adulto não apresenta grande espontaneidade ao expressar suas primeiras sentenças em uma LE. Ele acrescenta, ainda, que a criança tende a assumir riscos com mais facilidade, ao mesmo tempo em que o adulto se mostra mais inibido. Ellis (2005) afirma que, além do público infantil ser extremamente curioso, desinibido e interessado, é também livre de preconceitos com uma capacidade grande em comparar culturas diferenciadas e apresenta grande interesse em se comunicar com falantes nativos de uma LE.

Percebe-se que, quando se fala de ILEC, é necessária uma série de circunstâncias favoráveis para que o objetivo de aprendizagem seja atendido com sucesso. Dessa maneira, o papel do professor torna-se um dos fatores mais importantes na aprendizagem de ILEC. Por isso, o processo de formação que o docente percorre até estar apto a atuar em sala de aula é extremamente significativo e merece uma investigação especial.

Conforme a Lei $\mathrm{n}^{\mathrm{o}} 13.415$ de $2017^{5}$, um professor que ministrará aulas para a educação básica (da Educação Infantil ao Ensino Médio) deve ter o curso de Formação de docentes ou Licenciatura. Já o Conselho Nacional de Educação, através da Resolução $n^{0} 7$, de 14 de dezembro de $2010^{6}$, completa que nas escolas que incluírem LE nos anos iniciais do Ensino Fundamental, o professor deverá ter licenciatura específica no componente curricular.

Porém, observa-se que são raras as instituições formadoras desses professores que tenham, ao menos, uma disciplina especificamente sobre ensino e aprendizagem de inglês para crianças. Para embasar essa afirmação, foram verificadas as matrizes curriculares de 18 cursos de Licenciatura em Letras Inglês (ou Licenciatura Português e Inglês) de universidades federais de vários Estados do país ${ }^{7}$, buscando por disciplinas específicas de ensino para criança nos cursos de Letras (Quadro 1).

Quadro 1: Dados referentes às grades curriculares dos cursos investigados

\begin{tabular}{|c|c|}
\hline & Licenciatura em Letras Inglês \\
\hline Apresentam disciplinas específicas & 5 \\
\hline Não apresentam disciplinas específicas & 18 \\
\hline
\end{tabular}

Fonte: As autoras, 2020. 
Das 18 grades curriculares investigadas, cinco instituições dispõem de uma disciplina que apresenta "Ensino básico" na nomenclatura. Dentro dessas cinco selecionadas, há quatro casos de disciplinas relacionadas à Organização e Legislação do Ensino Básico e um caso de Conteúdos da Educação Básica para o Ensino de Língua Estrangeira. Vale ressaltar que as nomenclaturas Educação básica ou Ensino básico incluem desde o primeiro ano da Educação Infantil até o último ano de Ensino Médio, o que implica que as disciplinas não têm como foco apenas o Ensino Fundamental I. Podemos perceber, ainda, a disciplina obrigatória de Didática presente na matriz curricular de oito instituições pesquisadas. Além disso, cinco universidades oferecem como disciplina obrigatória também a disciplina de Fundamentos e Metodologias de Ensino de Lingua Inglesa. Consideramos constatações positivas, entretanto a pesquisa aqui apresentada não foi tão a fundo ao ponto de verificar as ementas das matérias. Por isso, não se sabe se os conteúdos apresentados abordavam o público infantil. Podemos perceber, assim, a presença de lacunas nos conhecimentos básicos para o docente nas universidades pesquisadas por não abordar a prática do ensino para crianças.

Deve-se mencionar, ainda, que a Base Nacional Comum Curricular (BNCC, 2017) e os Parâmetros Curriculares Nacionais (PCNs): Língua Estrangeira (2000) preveem o ensino de LE apenas a partir do Ensino Fundamental II. Tonelli et al. (2017), ao analisarem todas as teses defendidas sobre o ensino de LEC até o ano de 2013, trazem um apontamento relevante:

Um dos temas comumente mencionados nos trabalhos identificados, o qual ainda encontra espaço para pesquisas futuras, é a falta de políticas educacionais e de diretrizes para o ensino de LEC (TONELLI et al., 2017, p. 33).

Assim, embora não esteja previsto nos documentos mencionados, o que se observa é uma expansão significativa de ILEC no Brasil. Colombo e Consolo (2016) fazem um alerta do grande gap que há entre a prática do ensino de ILEC em escolas brasileiras e a falta de diretrizes governamentais de como fazê-lo, "uma vez que se legaliza a realização do ensino, mas não se tem bases específicas para implementá-lo" (p. 57). Faz-se necessária, assim, uma reflexão acerca da implementação de ILEC no Brasil.

\section{METODOLOGIA}

Esta pesquisa qualitativa concretizou-se na aplicação de um questionário on- 
line elaborado a partir dos conceitos de Dörnyei (2002) e constituído por perguntas abertas e fechadas. As próximas seções serão compostas por considerações a respeito do questionário e dos participantes, respectivamente.

\section{O questionário}

Os dados de análise desta pesquisa foram gerados por meio de um questionário elaborado na ferramenta on-line chamada Formulários Google, disponível gratuitamente pelo Google Drive. O questionário (Apêndice A) foi dividido em três seções com um total de 32 questões, sendo 24 fechadas e oito abertas. A seção I, denominada Perfil Pessoal, tinha como objetivo traçar um perfil dos participantes ao perguntar sobre idade, sexo, nacionalidade e se já haviam morado em outro país. Já a segunda seção, Perfil Profissional, buscava compreender a realidade de ensino na qual o professor atua, logo continha perguntas em que o participante deveria especificar se a escola em que trabalha é pública ou privada, se o tipo de ensino é regular, bilíngue ou internacional e em quais turmas o participante atua, entre outras. Finalmente, a seção III, nomeada Formação Acadêmica, tinha foco no tema principal da pesquisa e teve como objetivos compreender o histórico de formação inicial do participante e se o conhecimento fornecido em sua formação acadêmica foi suficiente para a prática docente. É somente nessa seção que as perguntas abertas aparecem, visando esclarecer de forma mais objetiva e crítica a graduação pela qual os participantes passaram.

Para a análise dos dados, foi necessário pedir aos participantes que concordassem com um Termo de Consentimento Livre e Esclarecido de forma a garantir os direitos dos participantes quantos às informações fornecidas. Assim como os questionários, o termo foi enviado por meio da ferramenta Formulários Google.

\section{Os participantes}

Como critério para a seleção, decidiu-se que os participantes desta pesquisa fossem professores de inglês atuantes no Ensino Fundamental I, pois estão diretamente envolvidos na prática docente com crianças e, para isso, passaram por uma formação inicial, foco desta pesquisa. Devido à intenção de coletar dados em diferentes contextos e não somente em uma escola específica, o contato se deu por meio de endereço eletrônico e os professores foram selecionados a partir de contatos prévios das pesquisadoras. Como uma das autoras deste trabalho é professora em curso de Letras, entrou em contato com 
professores de diferentes instituições com os quais tinha uma relação prévia a partir de atividades do curso como Estágio Supervisionado ou cursos ofertados. Algumas das professoras são, inclusive, ex-alunas desse curso de Letras e muitas das contactadas indicaram colegas que poderiam participar da pesquisa.

Todas as 14 professoras que participaram desta pesquisa são do sexo feminino, brasileiras que trabalham em escolas privadas de Curitiba (PR). Quanto à nacionalidade, $100 \%$ das participantes são brasileiras. Sobre a função, somente a participante D é professora auxiliar enquanto todas as outras são professoras regentes. O Quadro 2 as caracteriza de forma anônima, sendo assim, cada professora será reconhecida por uma letra de A a N. As informações contidas nesta seção foram retiradas a partir das respostas de 1 a 14 do questionário aplicado (Seção 1 - Perfil Pessoal e Seção 2 - Perfil Profissional).

Quadro 2: Informações das participantes

\begin{tabular}{|c|c|c|c|c|c|c|c|}
\hline $\begin{array}{c}\text { Partici- } \\
\text { pante }\end{array}$ & Idade & $\begin{array}{c}\text { Morou } \\
\text { fora }\end{array}$ & $\begin{array}{c}\text { Tempo que } \\
\text { leciona }\end{array}$ & $\begin{array}{c}\text { Onde } \\
\text { leciona }\end{array}$ & Turma & $\begin{array}{c}\text { Carga } \\
\text { horária } \\
\text { semanal }\end{array}$ & $\begin{array}{c}\text { Horas/ } \\
\text { Turma }\end{array}$ \\
\hline A & 25 & Não & 4 a 6 anos & $\begin{array}{c}\text { Escola } \\
\text { regular }\end{array}$ & $\begin{array}{c}4^{\circ} \text { e } 5^{\circ} \\
\text { ano }\end{array}$ & 32 horas & 2 horas \\
\hline B & 31 & Não & 4 a 6 anos & $\begin{array}{c}\text { Escola } \\
\text { bilíngue }\end{array}$ & $5^{\circ}$ ano & 30 horas & 30 horas \\
\hline C & 25 & Não & 4 a 6 anos & $\begin{array}{c}\text { Escola } \\
\text { bilíngue }\end{array}$ & $2^{\circ}$ ano & 24 horas & 9 horas \\
\hline D & 23 & Não & 8 a 10 anos & $\begin{array}{c}\text { Escola } \\
\text { bilíngue }\end{array}$ & $2^{\circ}$ a $5^{\circ}$ & 30 horas & $\begin{array}{c}45 \\
\text { ano }\end{array}$ \\
\hline E & 36 & Sim & +10 anos & $\begin{array}{c}\text { Escola } \\
\text { bilíngue }\end{array}$ & $4^{\circ}$ ano & 44 horas & 30 horas \\
\hline F & 27 & Não & -1 ano & $\begin{array}{c}\text { Escola } \\
\text { bilíngue }\end{array}$ & $1^{\circ}$ ano & 30 horas & 30 horas \\
\hline G & 23 & Não & 1 a 2 anos & $\begin{array}{c}\text { Escola } \\
\text { bilíngue }\end{array}$ & $1^{\circ}$ ano & 35 horas & 35 horas \\
\hline H & 24 & Não & 2 a 4 anos & $\begin{array}{c}\text { Escola } \\
\text { bilíngue }\end{array}$ & $4^{\circ}$ e $5^{\circ}$ & 14 horas & 2 horas \\
\hline I & 24 & Não & 6 a 8 anos & $\begin{array}{c}\text { Escola } \\
\text { bilíngue }\end{array}$ & $4^{\circ}$ ano & 25 horas & 25 horas \\
\hline & 45 & Sim & +10 anos & $\begin{array}{c}\text { Escola } \\
\text { bilíngue }\end{array}$ & $5^{\circ}$ ano & 35 horas & 30 horas \\
\hline
\end{tabular}




\begin{tabular}{|c|c|c|c|c|c|c|c|}
\hline $\mathbf{K}$ & 27 & Não & 2 a 4 anos & $\begin{array}{c}\text { Escola } \\
\text { interna- } \\
\text { cional }\end{array}$ & $1^{\circ}$ ano & 40 horas & 35 horas \\
\hline $\mathbf{L}$ & 52 & Sim & +10 anos & $\begin{array}{c}\text { Escola } \\
\text { bilíngue }\end{array}$ & $\begin{array}{c}3^{\circ} \text { a } 5 \\
\text { ano }\end{array}$ & 18 horas & 2 horas \\
\hline $\mathbf{M}$ & 26 & Não & 2 a 4 anos & $\begin{array}{c}\text { Escola } \\
\text { regular }\end{array}$ & $1^{\circ}$ ano & 12 horas & 4 horas \\
\hline $\mathbf{N}$ & 48 & Não & +10 anos & $\begin{array}{c}\text { Escola } \\
\text { bilíngue }\end{array}$ & $4^{\circ}$ ano & 30 horas & 30 horas \\
\hline
\end{tabular}

Fonte: As autoras, 2020.

Com base no Quadro 2, percebe-se que as professoras têm entre 23 e 52 anos, com uma média de idade de 31 anos e três delas tiveram a experiência de morar fora do Brasil. Chama a atenção o fato de a maioria das participantes atuar em escolas bilíngues (um total de 11). Assim, somente duas trabalham em escolas regulares e uma única em escola internacional. Percebe-se, ainda, que por serem grande parte professoras de escola bilíngue, a maioria das participantes dedica todo o tempo em sala de aula com a mesma turma, evitando o problema de pouca aula de inglês mencionado por Lightbown e Spada (2011).

\section{RESULTADOS}

Nesta seção, analisaremos as respostas do questionário na seção Formação acadêmica. Em um primeiro momento, será feito um histórico da formação de cada participante, seguido da análise dos seus cursos de graduação. Para isso, cada pergunta será examinada individualmente.

\section{Perfil acadêmico}

As perguntas de número 15 a 23 do questionário tiveram como objetivo investigar o histórico da formação inicial das professoras participantes desta pesquisa. Todas afirmam terem curso de graduação completo e a maioria é graduada no curso de Letras Português-Inglês. Das 14 participantes, somente uma se graduou em Pedagogia e duas em Letras Inglês. Além disso, somente duas participantes confirmaram terem curso de Formação Docente (antigo Magistério). 
Ao serem questionadas sobre como aprenderam a LI, as respostas foram bem variadas (Figura 1). Como a pergunta permitia que cada participante marcasse mais de uma opção, temos um número total de 33 respostas.

Figura 1: Caracterização dos conhecimentos de língua inglesa das participantes

\section{Caracterização dos conhecimentos de} língua inglesa dos participantes

14 respostas

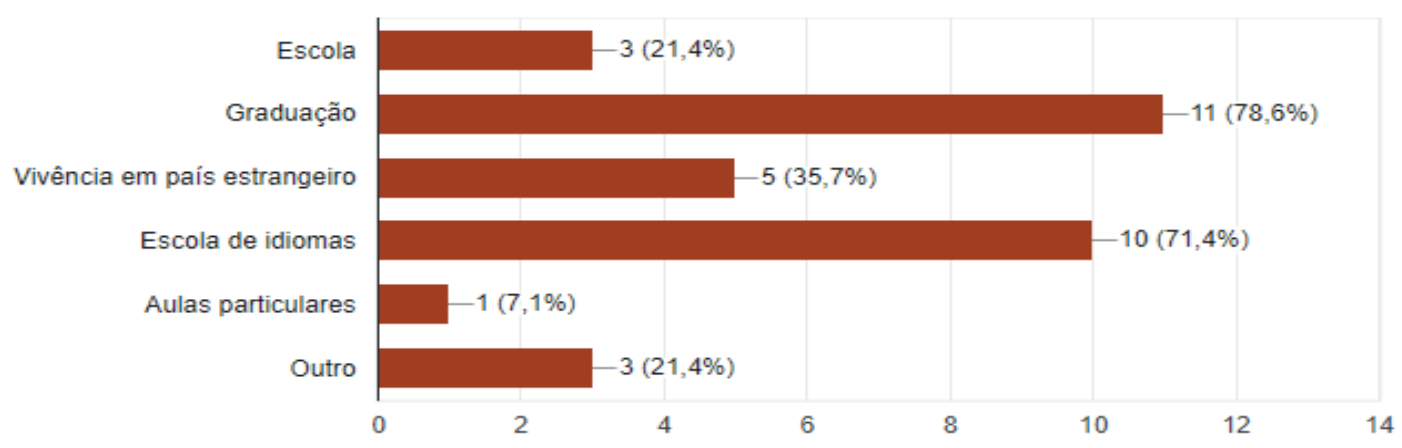

Fonte: As autoras, 2020.

A partir da Figura 1, pode-se perceber que a maioria das participantes, um total de 11, revela ter adquirido o conhecimento da LI na graduação. A segunda alternativa mais apontada é Escola de idiomas, escolhida 10 vezes como resposta e a terceira maneira de aprender LI mais marcada foi Vivência em país estrangeiro, eleita cinco vezes. Percebese que as duas formas mais apontadas estão relacionadas ao ensino formal do idioma.

Com relação ao Quadro Comum Europeu referente ao nível de conhecimento em LI, as participantes tinham acesso a um quadro de forma resumida e deveriam se autoavaliar e selecionar o nível em que cada uma se considera em LI. As opções $A 1$, A2 (nível básico e iniciante) e $B 1$ (autônomo e intermediário) não foram marcadas. Foram escolhidas as alternativas a partir do nível autônomo intermediário (B2). Quatro participantes (28,6\%) se consideram nível B2, enquanto a maior parte ( $50 \%$ ou sete participantes) se julga nível C1 (proficiente avançado) e três participantes $(21,4 \%)$ indicam ser nível C2 (proficiente avançado). Esse resultado é bastante positivo ao mostrar que a maioria dessas professoras se avalia em um nível de conhecimento de língua inglesa avançado, tornando-as aptas 
linguisticamente a exercer a profissão.

Ao questionar se as professoras cursaram ou estão cursando no momento alguma especialização dentro da área de LI ou ensino, 71,4\%, 10 de 14, responderam positivamente, o que nos traz respostas satisfatórias sobre a formação continuada delas. A pergunta seguinte fazia ligação ao apresentar as opções Especialização, Mestrado e Doutorado. Dentre as alternativas apresentadas, todas as 10 elegeram especialização.

Ainda sobre formação continuada, na próxima pergunta 92,9\%, isto é, 13 de 14 participantes asseguram ter o hábito de buscar essa formação, enquanto apenas uma das participantes assume não ter esse hábito. Considerando que todas as participantes já encerraram seu período de graduação, é importante ter a maioria das respostas positivas a essa pergunta, pois sabe-se que profissionais da educação devem estar sempre atualizados sobre questões relacionadas ao seu cotidiano. A profissão exige, portanto, constante ressignificação, transformação e aperfeiçoamento por parte do professor e a formação continuada é o principal caminho para esse progresso.

\section{Prática docente atrelada à formação}

Esta seção analisa as respostas de 24 a 32 do questionário. Com o objetivo de investigar se e como foram ofertados estudos voltados ao ensino de inglês para crianças na formação inicial das professoras, foi perguntado: "Dentro da sua graduação, você teve alguma disciplina que abordou o ensino de inglês para crianças? Se sim, qual? Ela foi optativa ou obrigatória?”. Com base nas respostas das participantes foi gerada a Figura 2.

Figura 2: Disciplinas do curso de graduação especificamente ensino de inglês para crianças

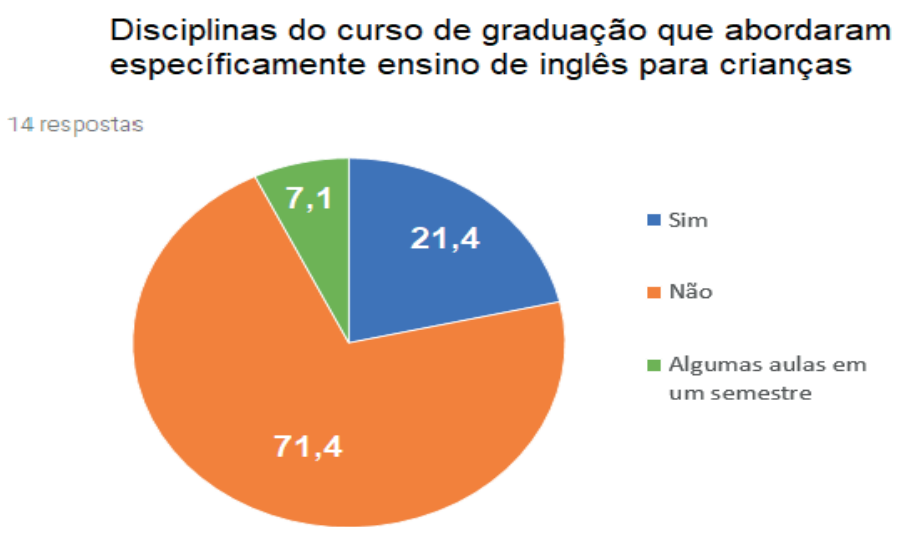

Fonte: As autoras, 2020. 
Para essa pergunta, somente três participantes $(21,4 \%)$ responderam positivamente. Uma participante $(7,1 \%)$, ainda, afirma não ter uma disciplina totalmente dedicada ao ensino ILEC, mas teve algumas aulas durante um semestre do curso, fato esse considerado positivo, porém, ainda insuficiente ao considerar como formação de docente de ILEC. Dez das participantes $(71,4 \%)$ negam terem tido alguma disciplina específica de inglês para crianças durante a graduação, o que pode dificultar sobremaneira a prática docente dessas professoras.

Com o objetivo de destacar aspectos fundamentais da formação para o trabalho com crianças, as participantes responderam a pergunta " $O$ que você considera que na sua formação foi fundamental para o tornar apto a dar aula de inglês para crianças?"». Um total de quatro participantes declarou que a prática ou experiência foi de fundamental relevância, uma vez que a formação não teve um peso muito importante: "Não tive essa abordagem na graduação. Tive que vivenciar na prática" (Transcrição da resposta da professora B), "aprendi na prática" (professora E). Três professoras revelam que uma disciplina ou mais de sua formação foram favoráveis: "algumas matérias de didática que foram ofertadas no decorrer do curso" (professora D). Três participantes afirmam não terem contado com disciplinas ou conteúdos específicos durante a formação: "Não tive aulas dentro dessa temática" (professora F). Percebe-se que a formação inicial não preparou suficientemente as professoras para o momento da prática de ILEC, pois a maioria delas relata que não teve disciplinas ou conteúdos relacionados durante a licenciatura.

Uma das soluções é buscar por outros recursos, como relatado pela participante A: "Como eu não tive nenhuma formação acadêmica sobre ensino de língua estrangeira para crianças, o que me ajudou e ainda ajuda muito foram orientações de professores formados em pedagogia, professores de inglês que trabalham há mais de 20 anos com ensino de LEM para crianças, a prática e vivência e também os estudos que procurei e estudei by myself sobre ensino". Também há os casos de aprendizado na prática, como foram as respostas de quatro participantes citadas acima (professoras A, B, C e E), os quais geralmente acontecem na base de tentativas, experimentos, erros e acertos. $\mathrm{O}$ fato de os cursos de formação inicial não tratarem das especificidades do ensino de inglês para o contexto da Educação Infantil e Anos Iniciais pode gerar como implicações professoras que, sem ter aporte teórico-metodológico, precisam vivenciar na prática para conseguir alcançar um resultado e, ainda, por ser uma tentativa, não se sabe ao certo se o resultado

\footnotetext{
${ }^{8}$ Para esta questão foram desconsideradas duas respostas devido a uma dificuldade de interpretação das participantes. Dörnyei (2002) relata que esse é um problema comum porque os participantes com frequência leem ou interpretam as perguntas de forma equivocada.
} 
é sempre positivo.

Com a pergunta "Além da sua formação, que outros recursos você buscou para auxiliá-lo a trabalhar com crianças?”, foi possível descobrir algumas fontes de recursos buscadas pelas professoras (Quadro 3).

Quadro 3: Recursos buscados para auxiliar no trabalho com crianças

\begin{tabular}{|c|l|}
\hline Participante & \multicolumn{1}{c|}{ Resposta } \\
\hline A & "A coordenação, professores, jogos que eles possam produzir e brincar". \\
\hline B & "Vídeos, tutoriais, busca por material na Internet". \\
\hline C & "Leitura, pesquisa e observação de aulas". \\
\hline D & $\begin{array}{l}\text { "Sempre estive em contato com crianças e tento ao máximo aprender com } \\
\text { colegas que têm mais experiência, mas nunca fiz um curso específico para a } \\
\text { área". }\end{array}$ \\
\hline E & "Fiz uma especialização em Educação Infantil". \\
\hline F & "Cursos, palestras, oficinas e seminários relacionados à educação". \\
\hline G & $\begin{array}{l}\text { "Sinceramente, busquei aprender por meio da observação de outras } \\
\text { professoras com a mesma formação que a minha que estavam atuando com } \\
\text { crianças, além da troca de experiência com elas. Além disso, também busquei } \\
\text { a pós em Psicopedagogia que, embora não auxilie no ensino }\end{array}$ \\
\hline H & $\begin{array}{l}\text { específico de língua inglesa, dá um ótimo embasamento para o trabalho com } \\
\text { crianças". }\end{array}$ \\
\hline I & "Materiais didáticos e conhecimento (dicas) de colegas professores". \\
\hline J & "Estudo contínuo". \\
\hline K & "Experiência". \\
\hline M & $\begin{array}{l}\text { "Fiz a pós de alfabetização, conversei e pedi auxílio para pedagogos e para } \\
\text { minha gestora - que me deu um grande suporte em meu primeiro ano em sala } \\
\text { de aula". }\end{array}$ \\
\hline "Música... filmes... jogos". \\
\hline "Treinamento na escola e pesquisas por conta própria". \\
\hline
\end{tabular}

Fonte: As autoras, 2020.

Ao analisar as respostas, percebe-se que 50\%, um total de sete participantes, relata que colegas de trabalho mais experientes ajudaram positivamente, seja pela troca de informações e experiências ou ao fazer observações do momento de prática, como 
relatado pela protessora $\mathrm{G}$, por exemplo. Ainda, seis participantes alegam cursos como um recurso, dentre eles cursos de especialização, magistério, treinamento e cursos específicos. Por fim, cinco participantes revelam recorrer a constantes pesquisas de fontes diversas. Pode-se perceber que há uma união da comunidade de professores de ILEC, pois existe uma troca de informações efetivamente positiva, conforme mencionado por metade das participantes, para a prática docente. Também se percebe que as professoras buscam por formação continuada, pois 11 delas relatam procurar por cursos, treinamentos ou pesquisas como fonte de ajuda.

Com a intenção de saber a opinião das professoras com relação à formação inicial pela qual passaram, fizemos o seguinte questionamento: "Em sua opinião, quais são as limitações do seu curso de graduação na formação de um professor de inglês para crianças?". As respostas apresentam algumas críticas em relação à graduação. Para essa pergunta, apenas uma professora aponta não ter limitações durante a graduação e uma outra considera o nível de LI insuficiente para a prática profissional. Já a maioria, um total de 11 participantes, relata não ter tido uma graduação focada para o ensino de ILEC e/ou que a graduação não preparou para a prática docente de ILEC. Há, portanto, uma grande insatisfação quanto aos conteúdos apresentados a essas professoras no momento de formação inicial. Uma das participantes até mostra-se consciente da realidade e propõe uma mudança para que se haja solução: "Como a BNCC não prevê o ensino de LEM no $\mathrm{EF} 1$, os cursos de graduação acabam não trabalhando esse ramo, apesar de a educação bilíngue ter se tornado muito forte nos últimos anos e desencadeado muitas mudanças curriculares, principalmente nas escolas privadas. Acredito que é necessário a inserção do ensino de LI na grade curricular dos cursos de graduação em Letras e Pedagogia para que o ensino dessa língua seja formativo e prático para essa nova realidade" (professora A).

A professora $\mathrm{C}$ também aborda a questão do Estágio Obrigatório, que na maioria das vezes é cursado em turmas do Ensino Fundamental II ou Ensino Médio: “Acredito que a graduação não focou o suficiente no ensino bilíngue e aquisição da língua nesse contexto, o que costuma acontecer nos primeiros anos do Ensino Fundamental 1. Ao mesmo tempo, o trato com crianças é muito diferente e, embora alguns graduandos tenham tido a oportunidade de entrar em contato com salas de Fundamental 1 durante o estágio, eu atuei apenas com o Fundamental 2" (professora C). Essa afirmação é, de certa forma, positiva, pois apesar de não ter sido o caso da participante em questão, ela relata que outros colegas tiveram a oportunidade de estagiar em turmas do Ensino Fundamental I, o que propiciou a eles um primeiro contato com as particularidades do público infantil.

Outra questão que teve como objetivo saber a opinião das participantes referente 
à graduação pela qual passaram apresenta o seguinte enunciado: "Você considera que a sua formação na graduação lhe proporcionou conhecimentos suficientes para a sua prática docente? Por quê?” (Figura 3).

Figura 3: Consideração se a graduação proporcionou conhecimentos suficientes para a prática docente

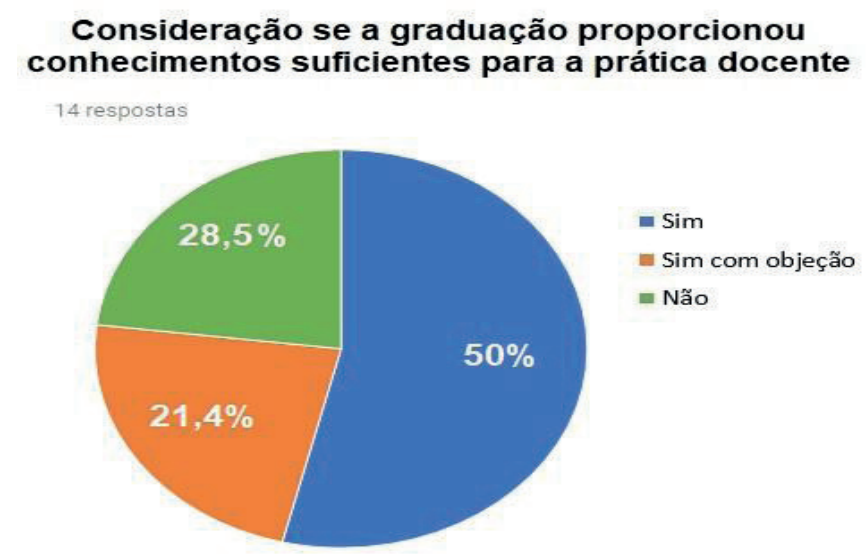

Fonte: As autoras, 2020.

Para essa pergunta houve 10 respostas afirmativas e quatro respostas negativas. Dentro da porcentagem de $28,5 \%$, os quais responderam de forma negativa, há críticas em relação à formação pela qual passaram, pois muitas se viram despreparadas para o momento da prática. Duas participantes especificamente comentaram sobre as implicações do método bilíngue. Uma delas expõe: "Suficientes, não. Porque eu sei como dar aula de inglês a fim de ensinar a língua propriamente dita, no entanto, ensinar outros conteúdos diversos utilizando a língua inglesa - que é a proposta do currículo bilíngue - e, ainda assim, manter o foco no aprendizado da língua, é um grande desafio, especialmente quando isso tudo é com foco em crianças de 6 anos" (professora G). É importante perceber que a professora de ensino bilíngue enfrenta grandes dificuldades, pois compete a esse profissional cumprir todo o conteúdo programático do currículo completamente em LI de forma a vencer as barreiras de compreensão em uma LE. Santana (2015) ressalta que enquanto graduandos não há uma compreensão definida a respeito de ensino bilíngue, principalmente por não se tratar do assunto durante a formação: "Isto se deve em primeiro lugar, ao fato dos cursos de formação de professores não estarem tratando do tema" (SANTANA, 2015, p. 99). 
Das 10 professoras que afirmaram considerarem ter tido conhecimento suficiente durante a formação, três complementam com alguma objeção, como declarar que consideram buscar aprimoramentos específicos para a área em que atuam. De acordo com a professora K, “Acredito que para o fundamental I e médio, sim. Tivemos bastante aulas para aperfeiçoar o inglês, metodologia, estágio, os professores são abertos para ajudar. Acho que hoje em dia, eu pensaria que faltou um pouco sobre metodologias diferentes, como a que trabalho (o IB), sequências didáticas e temáticas e sobre letramento literário também em língua inglesa" (professora K). Pode-se perceber que as participantes consideram os conhecimentos garantidos na sua formação relevantes, porém não suficientes para a prática em que se encontram: "Sim, mas para dar aulas para crianças foi necessária uma pesquisa pessoal" (professora $\mathrm{M}$ ).

As outras sete participantes que responderam de forma afirmativa a essa pergunta, ou seja, que consideram que a graduação proporcionou conhecimentos suficientes para a prática atribuem esse fato, em grande parte, às disciplinas de estágio e metodologias: "Considero, pois fui exposta a diversas metodologias que não conhecia e pude colocá-las em prática com os estágios supervisionados" (professora D). Dessa forma, somente 50\% das professoras consideram que a sua formação proporcionou conhecimentos suficientes para a prática sem acrescentar alguma crítica, ainda assim as respostas são positivas no que tange à formação inicial dessas participantes.

A pergunta seguinte questiona qual atividade ou disciplina da graduação a participante considera ter sido fundamental para a sua formação. Para essa pergunta foram citadas várias disciplinas dos cursos de graduação (Quadro 4).

Quadro 4: Atividades da graduação consideradas fundamentais para a formação

\begin{tabular}{|c|l|}
\hline Participante & \multicolumn{1}{c|}{ Resposta } \\
\hline A & Na minha opinião são as aulas de Língua Inglesa, Linguística e Tradução. \\
\hline B & Linguística Aplicada, Metodologia de ensino. \\
\hline C & Estágio. \\
\hline D & Estágios supervisionados. \\
\hline E & Metodologia. \\
\hline F & Psicologia Educacional, Fundamentos da Educação, Biologia Educacional. \\
\hline G & $\begin{array}{l}\text { Acredito que as disciplinas que foram mais valiosas na graduação foram } \\
\text { todos os estágios e, também, as disciplinas de metodologia - tanto em língua } \\
\text { inglesa, como portuguesa - pois deram um embasamento teórico interessante }\end{array}$ \\
\hline
\end{tabular}




\begin{tabular}{|c|l|} 
& $\begin{array}{l}\text { para a prática. O PIBID }{ }^{9} \text { também é uma atividade sensacional, que proporciona } \\
\text { um entendimento maior de como as coisas, de fato, acontecem quando vamos } \\
\text { para a prática. }\end{array}$ \\
\hline $\mathbf{H}$ & $\begin{array}{l}\text { Práticas de Ensino na Língua Inglesa (sinceramente não me recordo se este } \\
\text { era o nome da disciplina, porém estudávamos a teoria e então como aplicar } \\
\text { em sala de aula). }\end{array}$ \\
\hline $\mathbf{I}$ & $\begin{array}{l}\text { Metodologia, Filosofia, Análise Linguística, Linguística Textual, Literatura } \\
\text { Infanto-Juvenil e etc. }\end{array}$ \\
\hline $\mathbf{J}$ & Ensino de inglês como segunda língua e os estágios. \\
\hline $\mathbf{K}$ & $\begin{array}{l}\text { Não consigo pensar em somente uma. Acho que desde as de inglês com o } \\
\text { livro didático até as de educação foram essenciais. Acredito que aproveitei } \\
\text { muito o curso. Os laboratórios de escrita em inglês foram maravilhosos e hoje } \\
\text { acredito que ter mais horas com esse enfoque ajudaria muito no entendimento } \\
\text { da gramática da língua. }\end{array}$ \\
\hline $\mathbf{L}$ & Prática. \\
\hline $\mathbf{M}$ & Prática do Ensino de língua Inglesa I. \\
\hline $\mathbf{N}$ & Nível melhor de inglês. \\
\hline
\end{tabular}

Fonte: As autoras (2020)

Conforme o Quadro 4, a disciplina mais citada foi Metodologia de ensino, mencionada por quatro participantes. Em segundo lugar, apontadas três vezes, temos: Prática do ensino de língua inglesa, Estágio supervisionado e Linguística Aplicada. Podemos reparar que as quatro disciplinas mais mencionadas pelas participantes, com exceção de Linguística Aplicada, possuem ementas que envolvem a prática de ensino e podem ter focado nos aspectos importantes do público infantil relatados por autores como Brown (2001) e Ellis (2005).

É importante ressaltar que, dentre as 14 participantes, somente uma cursou Pedagogia, enquanto as outras 13 passaram pelo curso de Letras Português-Inglês ou Letras Inglês. Esse dado influencia diretamente as disciplinas mais mencionadas nesta resposta. Tomando como exemplo a resposta: "Psicologia Educacional, Fundamentos da Educação, Biologia Educacional” (professora F), é perceptível um destaque para a resposta dada pela professora formada em Pedagogia, pois são citadas duas disciplinas relacionadas ao desenvolvimento físico e mental da criança.

Merece destaque também a participante que explica não conseguir selecionar

\footnotetext{
${ }^{9}$ Programa Institucional de Bolsas de Iniciação à Docência do Ministério da Educação.
} 
pontos específicos (participante K), pois ela considera que o curso como um conjunto todo foi fundamental para sua formação. Ainda, a única participante que cita uma atividade relata que, além das disciplinas de estágio e metodologia, o PIBID foi uma experiência muito importante: "O PIBID também é uma atividade sensacional, que proporciona um entendimento maior de como as coisas, de fato, acontecem quando vamos para a prática" (professora G).

\section{Análise do termo indutor "ensino de inglês para criança"}

A última questão solicitou que as participantes escrevessem as cinco primeiras palavras que viessem à mente quando o assunto é "ensino de inglês para crianças". Das 14 participantes da pesquisa, 70 palavras foram relacionadas ao termo indutor; dessas, 68 serão analisadas.

Primeiramente, as palavras levantadas foram separadas em três campos semânticos. Os campos semânticos foram considerados similares ao focar no termo indutor em questão e são: ludicidade, abordagens e sentimentos do professor. Depois de separadas, as palavras foram quantificadas pelas vezes que foram mencionadas pelas participantes (Quadro 5).

Quadro 5: Elementos evocados com o termo "ensino de inglês para criança"

\begin{tabular}{|c|c|c|}
\hline $\begin{array}{c}\text { Campo semântico: } \\
\text { Ludicidade }\end{array}$ & $\begin{array}{c}\text { Campo semântico: } \\
\text { Abordagens }\end{array}$ & $\begin{array}{l}\text { Campo semântico: } \\
\text { Sentimentos do professor }\end{array}$ \\
\hline Palavra ( $n^{0}$ vezes citada) & Palavra ( $n^{0}$ vezes citada) & Palavra ( $n^{\circ}$ vezes citada) \\
\hline $\begin{array}{l}\text { Música (3) } \\
\text { Lúdico (3) } \\
\text { Diversão (3) } \\
\text { Jogos (2) } \\
\text { Filme (1) }\end{array}$ & $\begin{array}{c}\text { Dinâmica (3) } \\
\text { Diversidade (2) } \\
\text { Comunicação (2) } \\
\text { Oralidade (2) } \\
\text { Inovação (2) } \\
\text { Naturalidade (1) } \\
\text { Leveza (1) } \\
\text { Conversação (1) } \\
\text { Imersão (1) } \\
\text { Repetição (1) }\end{array}$ & $\begin{array}{c}\text { Paciência (4) } \\
\text { Desafio (3) } \\
\text { Dedicação (2) } \\
\text { Atenção (2) } \\
\text { Carinho (2) } \\
\text { Respeito (2) } \\
\text { Realização (1) } \\
\text { Cativante (1) } \\
\text { Encantador (1) }\end{array}$ \\
\hline
\end{tabular}




\begin{tabular}{|l|c|} 
Internacionalismo (1) & \\
Motivação (1) & \\
Visual-sonoro-tátil (1) & \\
Multidisciplinar (1) & Adaptação (1) \\
Rápido (1) & Amor (1) \\
Aulas diferenciadas (1) & Afetividade (1) \\
Letramento (1) & Sensível (1) \\
Senso crítico (1) & Colaboração (1) \\
Práticas sociais (1) & \\
Produção textual (1) & \\
Interação (1) & \\
Prática (1) & \\
\hline
\end{tabular}

Fonte: As autoras, 2020.

Verifica-se que dentro do campo semântico Sentimentos do professor as palavras que aparecem mais vezes são "paciência" em primeiro lugar e "desafio" em segundo lugar. Acredita-se que o trabalho docente em ILEC não é tido como simples e descomplicado pelas docentes, mas sim é um trabalho desafiador, o qual exige paciência. Em contraponto, dentro do mesmo campo semântico, pode-se perceber nove palavras de caráter positivo: "carinho"; "respeito"; "realização"; "cativante"; "encantador"; "amor"; "afetividade"; "sensível”; e "colaboração". Percebe-se, portanto, a presença de sentimentos positivos na lista das professoras.

Em segundo lugar como palavras mais induzidas, aparecendo três vezes, foram: "música"; "lúdico"; "diversão"; "dinâmica"; e "desafio". Percebe-se que três dessas palavras ("música", "lúdico" e "diversão") estão localizadas no campo semântico de ludicidade. O lúdico, portanto, é um termo considerado bastante significativo pelas participantes ao pensar em ILEC. Como já colocado anteriormente, é importante que a prática voltada para o público infantil seja divertida, motivadora e cativante, e o campo semântico ludicidade reflete a ocorrência dessa prática, que de acordo com Nikolov (1999) deriva resultados positivos.

O campo semântico mais preenchido foi o de abordagens, contendo 21 vocábulos 
diferentes. Dentro desse campo se destacam as palavras mais repetidas: "dinâmica"; "diversidade"; "comunicação"; "oralidade"; e "inovação". Ao considerar "dinâmica" e "diversidade", pode-se compreender que as professoras consideram a abordagem de ILEC ágil, ou seja, bastante ativa e variada, tais como os autores mencionados neste artigo. Percebe-se, ainda, que as abordagens levantadas, em sua maioria, fogem ao tradicionalismo do ensino de língua. Vocábulos como "naturalidade", "leveza", "conversação", "imersão", "multidisciplinar" e "aulas diferenciadas" nos remetem a uma busca das professoras por uma prática diferenciada que considera as particularidades do público infantil.

\section{CONSIDERAÇÕES FINAIS}

Neste artigo foi feita uma reflexão acerca da formação acadêmica dos professores de LI como língua estrangeira nos anos de Ensino Fundamental I.

Percebeu-se que há uma crescente promoção do ensino de ILEC, porém, pela não obrigatoriedade, esse ensino não é contemplado por documentos oficiais, como a BNCC e os PCNs. De acordo com a Lei no 13.415 de 2017 e o Conselho Nacional de Educação, através da Resolução $n^{0} 7$, de 14 de dezembro de 2010, a formação de docentes da educação básica deve se dar em licenciatura específica no componente curricular (no caso, Letras Inglês) ou em curso de nível médio na modalidade normal para professores de Educação Infantil e Ensino Fundamental I. Contudo, como foi verificado, muitos cursos de Letras Inglês não apresentam conteúdo específico sobre ensino de ILEC. Fazse necessária, portanto, a reformulação ou inclusão de algumas disciplinas sobre o ensino de inglês para crianças, bem como a elaboração de organização que regulamenta a oferta desse ensino, tal como mencionado por Colombo e Consolo (2016).

Ao analisar os dados coletados das professoras, constatamos falhas/ausências/ lacunas na formação acadêmica. Todas as 14 participantes revelam ter curso de graduação completa (dentre os cursos de Pedagogia, Letras Inglês ou Letras Português-Inglês) e serem atuantes no contexto de ensino de LI dos anos de Ensino Fundamental I. Assim, todas as professoras participantes apresentam a formação exigida por Lei. Entretanto, ao serem questionadas sobre os conhecimentos fornecidos pela graduação, percebemos algumas insatisfações ao confrontar a formação com o momento da prática docente. Somente quatro participantes (cerca de 28\%) afirmam, sem objeção alguma, que a graduação proporcionou conhecimentos suficientes para a prática, enquanto as outras 10 (cerca de 72\%) negam a mesma afirmação ou respondem afirmativamente com alguma objeção crítica à formação. Ainda, ao serem solicitadas para expor algum ponto da formação que foi fundamental 
para torná-las aptas para a prática com crianças, apenas cinco participantes conseguem nomear um ou alguns itens, enquanto as outras nove declaram não terem algo que lhes foi fundamental para a prática com crianças. Pode-se constatar a urgência de reformulação da formação dessas professoras, pois a graduação exigida por lei se mostra insuficiente para o momento da prática, não preparando as profissionais para a docência de ILEC em nível Fundamental I.

Os resultados obtidos com a pesquisa podem apontar para algumas implicações pedagógicas como consequência. Como relatado, as participantes enfrentam grandes dificuldades em sua prática e não se sabe, ao certo, até que ponto as professoras conseguem resolver os problemas de ensino-aprendizagem de seus alunos. Portanto, o despreparo para lidar com tais desafios pode implicar falhas na aprendizagem desses alunos. Há, também, os relatos de profissionais que aprendem na prática e na vivência em sala de aula. Algumas professoras se consideraram com preparo insuficiente para a prática e, mesmo assim, assumiram o desafio de entrar em sala e assumir o papel de regente. Portanto, as participantes parecem ter conseguido chegar às suas abordagens atuais na tentativa de abordagens consideradas adequadas por elas, processo esse que nem sempre é certeiro. Considera-se a possibilidade de as professoras terem passado por um processo de tentativas e resultados insatisfatórios também.

Dados apontam para um aspecto positivo, pois foi percebido que, apesar da formação insuficiente, as professoras não se mostram estagnadas e acomodadas. Treze declaram buscar por formação continuada e, ao responderem outras questões, é revelado também que há busca de diversos recursos por parte das professoras com o objetivo de aperfeiçoamento da prática.

Um dos fatores que limitou a pesquisa foi que, ao buscar pesquisas na área, pouco material foi encontrado e percebeu-se que dentro dos documentos políticos brasileiros o ensino de ILEC é praticamente inexistente. Outro fator limitador foi o fato de todas as respondentes que constituíram o corpus desta pesquisa serem atuantes em ensino privado. Portanto, a análise feita foi limitada à realidade do ensino em escolas privadas.

Propõem-se pesquisas na área em torno da instrução do professor de ILEC com o objetivo de futura reformulação da formação docente desse ensino. Pesquisas futuras podem se concentrar, ainda, na investigação da implementação do ensino de inglês no EF1 em escolas públicas para que todas as crianças tenham contato com outras culturas e possam desenvolver as habilidades de forma semelhante. 


\section{REFERÊNCIAS:}

BRASIL. Base Nacional Comum Curricular. MEC, 2017. Disponível em: http://www. planalto.gov.br/ccivil_03/_Ato2015-2018/2017/Lei/L13415.htm . Acesso em: 07 Jun. 2019.

BRASIL. Secretaria de Educação Básica. Parâmetros curriculares nacionais: língua estrangeira. Brasília: MEC, 2000. Disponível em: http://portal.mec.gov.br/dmdocuments/ rceb007_10.pdf. Acesso em: 07 Jun. 2019.

BROWN, D. Teaching by principles: an interactive approach to language pedagogy. New York: Pearson Education, 2001.

BREWSTER, J.; ELLIS, G.; GIRARD, D. The primary English teacher's guide. New Edition. London: Penguin, 2002.

COLOMBO, C. S.; CONSOLO, D. A. O ensino de inglês como língua estrangeira para crianças no Brasil: cenários e reflexões. São Paulo: Cultura Acadêmica, 2016.

DÖRNYEI, Z. Questionnaires in second language research: construction, administration and processing. Lawrence Erlbaum Associates, Estados Unidos da América, 2002.

ELLIS, R. Measuring implicit and explicit knowledge of a second language: a psychometric study. Studies in second language acquisition, v. 27, University of Auckland, Auckland, 2005 .

LIGHTBOWN, P. M.; SPADA, N. How languages are learned. Oxford University, 3rd edition, 2011.

MELLO, M. G. B. Ensino de inglês nos anos iniciais do ensino fundamental: um estudo de política pública no município de Rolândia, PR. Dissertação (Mestrado em Estudos da Linguagem) - Universidade Estadual de Londrina, Londrina, 2013.

MOON, J. Teaching English to young learners: the challenges and the benefits. In English, n. 5, 2005.

NIKOLOV, M. 'Why do you learn English?' 'Because the teacher is short.' A study of Hungarian children's foreign language learning motivation. Language Teaching Research 3, 1, 1999. 
SANTANA, A. C. C. Saberes docentes e representações sociais de estudantes de Pedagogia e Letras Português-Inglês sobre ensino bilíngue na pré-escola. Trabalho de Conclusão de Curso de Pedagogia da Pontifícia Universidade Católica do Paraná. Curitiba, 2015.

SANTOS, L. I. S.; SILVA, K. A.; JUSTINA, O. D. Entrevista com Kanavillil Rajagopalan: ponderações sobre linguística aplicada, política linguística e ensino-aprendizagem. Revista de Letras Norte@mentos, 8 ed., 2011.

TONELLI, J. R. A.; PÁDUA, L. S.; OLIVEIRA, T. R. R. Ensino e formação de professores de línguas estrangeiras para crianças no Brasil. Curitiba: Appris, 2017.

UR, P. A course in English Language teaching. Cambridge: CUP, 2012.

VICENTIM, K. A. Inglês nos anos iniciais do Ensino Fundamental público: de representações dos professores a políticas linguísticas. Dissertação (Mestrado em Linguística Aplicada). Universidade Estadual de Campinas, Campinas, 2013. 


\section{APÊNDICE A - QUESTIONÁRIO}

\section{Perfil pessoal}

1) E-mail:

2) Sexo ( ) F ( ) M

3) Idade: anos

4) Nacionalidade:

5)Você já morou em outro país? ( ) S ( ) N

6) Em caso afirmativo à pergunta anterior, em qual país morou e por quanto tempo?

\section{Perfil profissional}

7) Há quanto tempo você leciona?

( ) Menos de 1 ano

( ) Entre 1 e 2 anos

( ) Entre 2 e 4 anos

( ) Entre 4 e 6 anos

( ) Entre 6 e 8 anos

( ) Entre 8 e 10 anos

( ) Mais de 10 anos

8) Onde você leciona atualmente?

( ) Escola privada

( ) Escola pública

9) Onde a(s) escola(s) que você leciona está(ão) localizadas?

( ) Curitiba

( ) Região Metropolitana de Curitiba

( ) Outra cidade do Paraná. Qual? 
10) Qual é o tipo de escola que você leciona?

( ) Escola bilíngue

( ) Escola regular

11) Em qual(quais) turma(s) você dá aula atualmente?

( ) $1^{\circ}$ ano Ensino Fundamental I

( ) $2^{\circ}$ ano Ensino Fundamental I

( ) $3^{\circ}$ ano Ensino Fundamental I

( ) $4^{\circ}$ ano Ensino Fundamental I

( ) $5^{\circ}$ ano Ensino Fundamental I

( )Outra

12) Qual é a sua função?

( ) Professor auxiliar

( ) Professor regente

13) Qual é a sua carga horária semanal nessa escola? (Caso você lecione em mais de uma escola, especifique sua carga horária para cada escola)

14) Quantas horas por semana você tem em cada turma?

\section{Formação acadêmica}

15) Você possui curso de Formação de docente? ( ) S ( ) N

16) Você possui graduação completa? ( ) S ( ) N

17) Caso sua resposta seja afirmativa na pergunta anterior, em qual curso você se graduou?
( ) Pedagogia
( ) Letras Inglês
( ) Letras Português-Inglês
( ) Outro 
18) Como você obteve seu conhecimento de Língua Inglesa?

( ) Escola

( ) Aulas particulares

( ) Graduação

( ) Vivência em país estrangeiro

( ) Escola de idiomas

( ) Outro. Como?

19) Você frequentou algum curso de língua inglesa? ( ) $\mathrm{S}($ ) $\mathrm{N}$

20) Caso sua resposta tenha sido afirmativa na pergunta anterior, por quanto tempo?

( ) Menos de 6 meses

( ) De 6 meses a 1 ano

( ) De 1 a 2 anos

( ) De 2 a 3 anos

( ) De 3 a 4 anos

( ) De 4 a 5 anos

( ) 6 anos ou mais

21) Dentro do Quadro Europeu Comum de Referências para Línguas (CEFR), circule qual nível de Língua inglesa você considera ter. 


\begin{tabular}{|c|c|c|}
\hline \multirow[b]{2}{*}{ 遵 } & A1 & $\begin{array}{l}\text { Consegue interagir em situações simples do dia-a-dia como: expressar } \\
\text { desejos; necessidades; vontades, falar sobre si e sobre sua rotina diária. }\end{array}$ \\
\hline & A2 & $\begin{array}{l}\text { Consegue interagir em situaç̃os um pouco mais complexas como: descrever } \\
\text { pessoas; lugares; objetos, situações e emitir opiniões de maneira simples e } \\
\text { objetiva. }\end{array}$ \\
\hline \multirow{2}{*}{ 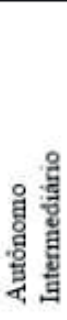 } & B1 & $\begin{array}{l}\text { Consegue demonstrar opiniões através de raciocínios simples, discernir com } \\
\text { mais clareza sobre passado, presente e futuro. }\end{array}$ \\
\hline & B2 & $\begin{array}{l}\text { Consegue se expressar com mais profundidade em assuntos em que possui } \\
\text { maior grau de conhecimento, dar exemplos, identificar problemas e apontar } \\
\text { soluções. }\end{array}$ \\
\hline \multirow[b]{2}{*}{ 苋这 } & C1 & $\begin{array}{l}\text { Consegue falar, ler, ouvir e escrever com maior grau de fluência, participar } \\
\text { ativamente em uma negociação, argumentar e concordar ou discordar de forma } \\
\text { adequada ao contexto. }\end{array}$ \\
\hline & C2 & $\begin{array}{l}\text { Consegue se expressar espontaneamente, de modo fluente e com exatidão, } \\
\text { sendo capaz de distinguir finas variações de significado em situações } \\
\text { complexas. }\end{array}$ \\
\hline
\end{tabular}
( ) A1
( ) $\mathrm{A} 2$
( ) B1
( ) B2
( ) $\mathrm{C} 1$
( ) $\mathrm{C} 2$

22) Você fez algum curso de especialização ou pós-graduação na área de língua estrangeira ou ensino?

23) Em caso afirmativo na pergunta anterior, assinale um dos níveis:

( ) Especialização

( ) Mestrado

( ) Doutorado

24) Você tem hábito de buscar uma formação continuada? ( ) S ( ) N

25) Em caso afirmativo na pergunta anterior, que tipo de atividades/cursos você costuma fazer? Em caso negativo, por que não? 
26) Dentro da sua graduação você teve alguma disciplina que abordou o ensino de inglês para criança? Se sim, qual? Ela foi optativa ou obrigatória?

27) O que você considera da sua formação que foi fundamental para ser apto a dar aula de inglês para criança?

28) Além da sua formação, que outros recursos você buscou para auxiliá-lo a trabalhar com crianças?

29) Em sua opinião quais são as limitações do seu curso de graduação na formação de um professor de inglês para criança?

30) Você considera que a sua formação na graduação the proporcionou os conhecimentos suficientes para a sua prática docente? Por quê?

31) Especifique qual atividade que você teve na graduação que você considera fundamental na sua formação.

32) Escreva as cinco primeiras palavras que vêm à sua mente quando se fala em "ensino de Inglês para criança".

Recebido em: 30 set. 2019

Aceito em: 31 mar. 2020 